\title{
Arsenic Pollution in Rural West Bengal - Exploring Some Challenges.
}

\author{
Sk. Rezaul Hoque \\ Guest-Lecturer, Department of Open and Distance Learning (DODL), Dinabandhu Mahavidyalaya Centre, \\ University of Kalyani, Nadia, West Bengal, India.
}

\begin{abstract}
The word Arsenic is always alarming to us. It is nothing but a prejudiced view. If we take arsenic through drinking water or in other forms, it is not always injurious to health. It is a matter of lookout weather its intake is within or beyond the danger level. All of us should be aware of the value of danger level. The present study deals with to create consciousness among the people in respect of danger level of arsenic in drinking water. The sample consist of 50(N=50) Tube Wells of different families gathered by Situational Sampling Technique from different rural areas of Habra Block, North 24 Parganas, West Bengal, India. The findings reveals that a large portion of the areas of North 24 Parganas, is dominated by arsenic pollution and people suffer from arsenic-stricken diseases because of their ignorance and lack of awareness regarding arsenic pollution and its impact on Human Health. Some remedial measures should be taken to generate awareness among general people from government, semi-government organizations, NGOs and other individual and collective efforts. Further studies are necessary in this regard.
\end{abstract}

Key words: Arsenic Pollution, Water level, Tube Well, Disease, Rural, Habra Block, West Bengal.

\section{Introduction :}

Today Arsenic pollution is a menace to all of us. A major part of India is affected by Arsenic pollution. Arsenic affected persons are spreading in various number in different parts of India. Specially in West Bengal this number is too high. Persons are being affected arsenic pollution in two ways namely (i) ignorance about arsenic pollution and (ii) in difference or lack of precaution about arsenic pollution.

Deep acting impact of Arsenic pollution on Human being, plants, other animals and Environment is much alarming. In different countries of the world like Mexico, Chilly, Argentina, India, Bangladesh, Myanmar, Arsenic pollution is increasing day by day. In West Bengal several district such as 24 Parganas (N \& S), Nadia, Burdwan, Malda etc. are being affected very badly. For analysis and finding the preventive measures, Project on Arsenic pollution is being done.

\section{Significance Of The Study:}

Excessive arsenic taking causes various diseases. Symptoms of arsenic pollution in a body should be identified and measure for treatment should be taken. For prevention, first of all arsenic taking should be always below the danger level $(0.05 \mathrm{mg} / \mathrm{lit})$ and if required, arsenic free water should be supplied. This tusk of solving the problem may be successfully done both by the Government and Non-Government Venture and there should be coordination between them. Most of the villagers of North 24 Parganas of West Bengal are affected by arsenic pollution. The pollution problem stands in the way of their economic property because it also harms the environment which is conductive to health.

So, this type of project is required to know how much potentiality for environment development and public health are wasted by the arsenic pollution and in what way this problem can be overcome. If we are able to find out any acceptable measure for this problem then the development of this area and public health will be sustainable.

\section{Sourses Of Arsenic :}

Arsenic is found widely in nature and most abundantly in sulphide ores. The arsenic loaded iron particles are then flushed into the sand layer below. The layer of fine sand traps the arsenic loaded iron particles in the top few centimeters, thus affectively removing arsenic. Sources of arsenic are-

1. Some travicides and rodenticides contain arsenic.

2. Arsenic is illegally used to prepare alcohol and induce abortion.

3. Factories where copper is melted, in one step of the process, arsenic is obtained as a by product.

4. Previously in many allopathic medicines arsenic was used. This practically not used now-a-days in modern medicine.

5. In agricultural fields to kill the herbs arsenic is used.

6. In pomphred and hilsa fish arsenic is found in greater amount than in any other fish. 
7. In some regions, in some layer of soil, arsenic may be there. Arsenic released through some chemical process and dissolved in the water of that layer. If the tube well pumps out water from the layer, arsenic may be present above the permissible limit.

8. High arsenic concentration in ground water is generally associated with the geochemical environments of volcanic deposits, geothermal system and being fill deposits of allured lacustrine origin

9. The principle sources of arsenic are from arsenic bearing geologic material. The presence of sulphide mineral deposits in the field and the association of arsenic with such types of minerals suggest very strongly that these are the origin for the near field arsenic sources.

10. Factual and anecdotal reports indicate that high concentrations of arsenic are grounded primarily in the upper 150 meters of the alluvial sediments.

\section{Harmful Effects Of Arsenic:}

Harmful effects of arsenic pollution has two division-

a) Acute poisoning

b) Chronic Poisoning

\section{a) Acute poisoning}

Actual poisoning may occur due to accidental ingestion of inorganic arsenic compounds (e.g. arsenic trioxide). Cases of poisoning are characterized by profound gastrointestinal damage, resulting in sever vomiting and diarrhea which may result in shock and subsequent oliguria and albuminuia. Other acute symptoms may occur within a few minutes following exposure to the poison in solution out may be delayed for several hours if the arsenic compound is solid form or if it is taken with a meal. When ingested as a particulate, toxicity is also dependent on solubility and particle size of the ingested compound.

The fatal dose of ingested arsenic trioxide has been reported to range from 70 to $180 \mathrm{mg}$./lit Death may occur within 24 hours but the usual course runs from 3 to 7 days. Actual intoxication with arsenic compounds is usually accompanied by anemia and leucopenia especially granulocy openia. In survivors these effects are usually reversible within 2 or 3 weeks. Reversible enlargement of the liver is also seen in acute poisoning.

Exposure to irritant arsenic compounds in air, such as arsenic trioxide can causes acute damage to mucous membranes of the respiratory systems and can cause acute symptoms from exposed skin. Severe irritation of the nasal mucosa, larynx and bronchi as well as conjunctivitis and dermatitis occur in such cases. A certain tolerance against acute poisoning is believed to develop upon repeated exposure. This phenomenon, however, is not well documented in the scientific literature.

\section{b) Chronic Poisoning}

Chronic arsenic poisoning may occurs in worker exposed for a long time to excessive concentration of airborne arsenic compounds. Local effects in the mucous membranes of the respiratory tract and skin effects are prominent features. Involvement of the nervous and circulatory systems and the liver may also occur as well as cancer of the respiratory tract.

With long term exposure to arsenic via ingestion in food, drinking water or medications, symptoms are partly different from those after inhalation exposure. Vague abdominal symptoms - diarrhoea or constipation, flushing of the skin, pigmentation and hyperkeratosis - dominate the clinical picture.

Anaemia and lucocytopenia often occur in chronic arsenic poisoning. Liver involvement has been more commonly seen in persons exposed for a long time via oral ingestion than in those exposed via inhalation.

Arsenical skin lesions are some what different depending on the type of exposure. Exzematoid symptoms of varying degrees of severity do occur. Two types of dermatological disorders may occur.

1) An eczematous type with erythema, swelling and papules or vesicles ; and

2) A follicular type with erythema and follicular swelling or follicular pustules.

Dermatitis is primarily localized on the most heavily exposed areas such as the face, back of the neck, forearms, wrists and hands. Chromic dermal lesions may occur depending on the concentration and duration of exposure. These chronic lesions may occur after many years of environmental exposure. Hyperkeratesis, warts and nekabisus of the skin and the conspicuous signs in chronic skin lesions poisoning depigmentation, i.e. Leukoderma, especially on the pigmented areas, commonly called 'raindrop' pigmentation also occurs. These chronic skin lesions, particularly the hyperkeratosis may develop into precancerous and cancerous lesions.

Mucous membrane lesions in chronic arsenic exposure are most classically reported as perforation of the nasal septum after inhalation exposure. This lesion is a result of irritation of the mucous membranes of the nose. 


\section{Objectives Of The Study :}

1. To determine the source of arsenic amongst the geologic material in the subtract.

2. To determine the relation between water level of Tube well and the quantum of Arsenic contents.

3. To determine the impacts of Arsenic on human body.

4. To determine the possible remedial measures to Arsenic Pollution.

\section{Methodology:}

Type of the research: The study is basically survey type research.

Sample : The sample was fifty(50) tube well of fifty different families collected by situational sampling technique from different rural areas of Habra Block, North 24 Parganas, West Bengal, India.

Tools : An interview schedule prepared by the researcher .

\section{Observation And Discussion:}

The study of the project reveals that a few people are aware of arsenic and its impact on the health and sanitation of the people. A large number of people are ignorant of arsenic pollution. They suffer from arsenic disease and become the victim of Arsenic pollution but they do not think of it. Most of the people in the area under survey are reluctant to the suffering from arsenic. When the impact of arsenic becomes actual and people suffer from Black foot disease then they can realize that they are suffering from arsenic pollution. When people suffer from different skin diseases, the body looks very rough, black spots are found on the hand and foot, people suffer from pain in big and liver. Some patches of blood are found on the joints and itching tendency is also found.

A large number of people residing in Atulia,Haria, Jeoldanga, Hirapole, Anoarberia, Raghabpur, Kalitala, Simulpur, Betpul etc. Villages of Habra Block, in the Dist. North 24 Parganas, West Bengal, India have been suffering from different arsenic prone diseases for a long time. Some people have also died in this area in last few years by suffering from arsenic prone diseases. So the experiences of the people under review are very miserable.

Table : Depth of Water Level of Tube Wells and the quantum of Arsenic Contents :

\begin{tabular}{|c|c|c|c|c|}
\hline $\begin{array}{c}\text { Name of the } \\
\text { Gram Panchayets }\end{array}$ & $\begin{array}{l}\text { Village } \\
\text { Name }\end{array}$ & $\begin{array}{l}\text { Location (House/ } \\
\text { Premises of) }\end{array}$ & $\begin{array}{c}\text { Dept. of the } \\
\text { water level (in } \\
\text { foot) }\end{array}$ & $\begin{array}{c}\text { Quantum of } \\
\text { Arsenic(mg/lit) }\end{array}$ \\
\hline 1. Prithiba & Atulia & Sannashi Das & 17 & 0.59 \\
\hline 2. -Do- & Atulia & Abdul Sahid & 24 & 0.30 \\
\hline 3. -Do- & Atulia & Golam Hossain & 40 & .025 \\
\hline 4. -Do- & Atulia & Majed Golder & 24 & 0.18 \\
\hline 5. -Do- & Atulia & Emdadul Haque & 50 & 0.72 \\
\hline 6. -Do- & Atulia & Ali Akbar & 50 & 0.93 \\
\hline 7. -Do- & Atulia & Rejaul Haque & 60 & 0.91 \\
\hline 8. -Do- & Atulia & Ali Hasan & 43 & 0.72 \\
\hline 9. -Do- & Atulia & Abu Jafar & 100 & 0.57 \\
\hline 10. -Do- & Atulia & Sirajul Islam & 112 & 0.07 \\
\hline 11. -Do- & Atulia & Sahidul Islam & 114 & 0.06 \\
\hline 12. -Do- & Atulia & Ram Das & 55 & 0.06 \\
\hline 13. -Do- & Atulia & Shankar Das & 57 & 0.30 \\
\hline 14. -Do- & Atulia & Bidhan Das & 59 & 0.09 \\
\hline 15. -Do- & Atulia & Abdul Khalil & 65 & 0.07 \\
\hline 16. -Do- & Haria & Julfikar Mondal & 69 & 0.08 \\
\hline 17. -Do- & Haria & Kayem Mondal & 79 & 0.06 \\
\hline 18. -Do- & Haria & Gaffar Mondal & 90 & 0.09 \\
\hline 19. -Do- & Haria & Nur Nabi Mondal & 99 & 0.06 \\
\hline
\end{tabular}


Arsenic Pollution In Rural West Bengal - Exploring Some Challenges.

\begin{tabular}{|c|c|c|c|c|}
\hline 20. -Do- & Haria & Lutfar Mondal & 87 & 0.07 \\
\hline 21. -Do- & Haria & Rabiul Mondal & 130 & 0.08 \\
\hline 22. -Do- & Haria & Matlubbar Mondal & 179 & 0.94 \\
\hline 23. -Do- & Anoarberia & Abul Kasem & 135 & 0.06 \\
\hline 24. -Do- & Anoarberia & Abdul Mannan & 200 & 0.05 \\
\hline 25. -Do- & Anoarberia & Manamistry & 97 & 0.90 \\
\hline 26. -Do- & Anoarberia & Mukul Mistry & 65 & 0.8 \\
\hline 27. -Do- & Jeoldanga & Ajijar Rarman & 114 & 0.7 \\
\hline 28. -Do- & Jeoldanga & Samsul Islam & 303 & 0.7 \\
\hline 29. -Do- & Jeoldanga & Jamir Mondal & 300 & 0.9 \\
\hline 30. -Do- & Jeoldanga & Mahadeb Das & 115 & 0.20 \\
\hline 31. -Do- & Hirapole & Hakim Mondal & 159 & 0.31 \\
\hline 32. -Do- & Hirapole & Samir Das & 219 & 0.23 \\
\hline 33. -Do- & Hirapole & Sankar Talukdar & 200 & 0.51 \\
\hline 34. -Do- & -Do- & Subir Ghosh & 80 & 0.8 \\
\hline 35. Machlandapur & Raghabpur & Anu Ghosh & 45 & 0.9 \\
\hline 36.-Do- & -Do- & Rajak Haldar & 95 & 0.9 \\
\hline 37.-Do- & -Do- & Ganesh Sen & 100 & 0.6 \\
\hline 38.-Do- & -Do- & Jahir Khan & 115 & 0.5 \\
\hline 39.-Do- & -Do- & Sourav Haldar & 69 & 0.9 \\
\hline 40.-Do- & Kalitala & Partha Roy & 201 & 0.6 \\
\hline 41.-Do- & -Do- & Susanta Das & 202 & 0.06 \\
\hline 42.-Do- & -Do- & Arnab Dutta & 304 & 0.05 \\
\hline 43.-Do- & -Do- & Debasish Das & 69 & 0.6 \\
\hline 44.-Do- & Shimulpur & Santan Dam & 79 & 0.6 \\
\hline 45.-Do- & -Do- & Kumar Ghosh & 101 & 0.8 \\
\hline 46.-Do- & -Do- & Sujoy Das & 100 & 0.4 \\
\hline 47.-Do- & Bethpul & Tamajit Mitra & 150 & 0.9 \\
\hline 48.-Do- & -Do- & Achinta Das & 175 & 0.2 \\
\hline 49.-Do- & -Do- & Sudipta Roy & 101 & 0.8 \\
\hline 50.-Do- & -Do- & Shimul Paul & 180 & 0.06 \\
\hline
\end{tabular}

The Study reveals that the arsenic tendency is increasing to some extent, when the depth of water level is increasing to certain limit. The surface water has the minimum content and it is higher when the water level is 200 to 400 feet. But below this level arsenic content in the water is minimum.

If the findings of the study become the general criteria of different villages of West Bengal then the coming days will be very alarming to the society.

\section{Conclusion \& Suggestion:}

The project reveals that a large portion of the areas of North 24 Parganas is dominated by arsenic and people suffer from arsenic-stricken diseases. A large portion of the people suffers from arsenic-stricken diseases because of their ignorance and negligency regarding arsenic and its impact on health and sanitation. Most of the people suffer because of unawareness and lack of precautionary measure against arsenic. If people become aware of impact of arsenic and use pure and arsenic free water then the probability of arsenic-stricken diseases 
will be minimum. It is also found that arsenic is everywhere should us, ready to gain unsuspected entrance to our bodies from the food we eat, the water we drink and the air we breathe.

If some measures are undertaken to reduce the arsenic toxicity and for that awareness generation is highly essential. In the beginning of this awareness, one must know the nutrition supplementation, i.e. high amino acid containing cereal, vegetables, along with antioxidants. Secondly, to avoid the arsenic contaminated water in cooking and drinking purpose, low cost homemade filter may be used for getting arsenic free water. Therefore, some simple and homemade technologies certainly reduce the arsenic toxicity. The present discussion regarding the awareness among the community will certainly be helpful to avoid arsenic exposure.

The problem of arsenic may be removed by adopting different measures, such as -

i) Creation of public awareness.

ii) Filtration of water.

iii) Use of surfaces water after boiling.

iv) Drinking of arsenic free water.

v) Testing of Drinking water at sometime interval.

vi) To make water arsenic free.

vii) Initiate by the NGO (Non Govt. Organization)

viii) Govt. plans and Programmes to supply arsenic free drinking water to the rural mass.

In fine, it may be concluded that this project will be helpful to create awareness among the people and make them free from arsenic-stricken disease. It may also be said that public awareness created by publicity by Govt. and Non-Govt. agencies is the only measure to be free from the grasp of arsenic.

\section{References:}

[1] Chatterjee d. "Geochemistry of Arsenic in the sediments of Bengal Delta Plan".

[2] Chakraborty R, University of Calcutta : Impact of Awareness of Arsenic on Health and Environment among the Rural People : a case study on the villages of North 24 Parganas.

[3] Das Indrani, Ghosh koushik and Sanyal S. K. of Bidhan Chandra Krishi Viswavidyalaya : "Phytoremediation of a potential option to mitigate arsenic contamination in soil-water plant system."

[4] Dey Madhusnata : "Oietary Protection Against Arsenic Toxicity."

[5] Dr. Gupta Anirban : Shibpur Engineering College.

[6] Gupta Anirban: "Arsenic-free Safe Water - An appropriate Technology."

[7] Kundu Ashok, Rishi Bankim Chandra College : "Arsenic Free Drinking Water : The Gontra Experience."

[8] Nath K.J. : "The new menace in Asia Arsenic is Ground Water and its impact on community Health."

[9] Poddar D. Chakraborty Arup and Banerjee Tarak : "Journey Towards Reduction of sufferings of the people of West Bengal from the clutch of Arsenic."

[10] Roy Choudhury A : "Arsenic exposure through drinking water creates health problem due to lack of awareness."

[11] Sahu Manabendra : "Alarming Arsenic Attacking Aquifers."

[12] Sanyal S. K. : "Arsenic contamination in Ground Water of the Bengal Delta Basin : Implications in Agricultural Systems." 